\title{
Einheit und Vielheit als metaphysisches Problem
}

\author{
Hrsg. v. Johannes Brachtendorf u. Stephan Herzberg
}

Einheit und Vielheit als metaphysisches Problem

Herausgegeben von JOHANNES BRACHTENDORF und STEPHAN HERZBERG

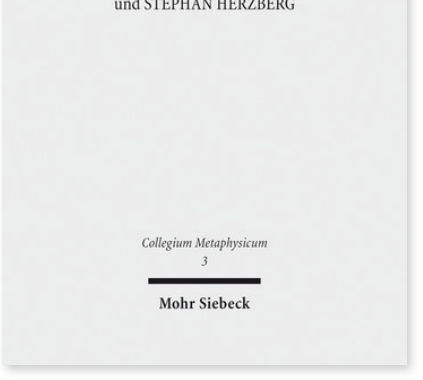

2011. VI, 243 Seiten. CM 3

ISBN 978-3-16-151749-5

DOI 10.1628/978-3-16-151749-5

eBook PDF 54,00€

ISBN 978-3-16-151033-5

fadengeheftete Broschur 54,00 €
Die Metaphysik versteht sich als eine Theorie der Wirklichkeit: Gegenüber dem, was sich etwa unseren Sinnen oder dem Alltagsverstand als wirklich darbietet, möchte sie uns mit Gründen darüber belehren, was es überhaupt heißt, wirklich zu sein, wie die Wirklichkeit aufgebaut ist und was ihre grundlegenden Strukturen sind. Hierfür geht sie in ihrer klassischen Gestalt von einem Ersten oder einem Prinzip aus.

Der vorliegende Band stellt das für eine prinzipienorientierte Metaphysik zentrale Begriffspaar von Einheit und Vielheit in den Mittelpunkt. Die Autoren diskutieren die Frage, ob man das Eine als Grund und Ziel aller Dinge ansetzen muss, um die Wirklichkeit zu verstehen, wie die henologische Tradition meint, oder ob die Realität auf irreduzible Weise von Vielheit und Andersheit geprägt ist. Erzeugt die Logik der Einheit bloß einen dialektischen Schein, den es aufzulösen gilt? Nivelliert sie gar die Differenz zwischen Gott und Welt? Oder lässt sich Einheit so verstehen, dass sie die Vielheit rechtfertigt und begründet? Der Sache nach geht es um das Verhältnis des Unendlichen zum Endlichen, des Absoluten zum Relativen oder der Identität zur Differenz. Die vorliegenden Beiträge decken Hauptstationen der Metaphysikgeschichte von Parmenides bis Lévinas ab.

Inhaltsübersicht

Johannes Brachtendorf / Stephan Herzberg: Einleitung: Die Metaphysik und das Problem von Einheit und Vielheit - Emil Angehrn: Einheit, Ganzheit, Identität. Zur Frühgeschichte des metaphysischen Denkens bei Parmenides - Stephan Herzberg: Pros hen- Einheit und Analogie. Die Vielheit des Seienden und das ontologisch Primäre bei Aristoteles und Thomas von Aquin - Jens Halfwassen: Einheit und Vielheit bei Plotin. Das Eine als absoluter Grund der Vielheit - Norbert Fischer: Schöpfungslehre und Christologie in Augustins Confessiones. Zu systematischen Grundlagen der Fragen nach Einheit und Vielheit im Denken Augustins - Markus Enders: Deus unus est. Meister Eckharts Metaphysik der Einheit und ihr intellekttheoretisches Fundament - Harald Schwaetzer: Einheit und Vielheit als Problem des Partizipationsgedankens bei Nikolaus von Kues - Jean Greisch: Einheit und Vielheit - eine Herausforderung für die transzendentale Dialektik - Anton Friedrich Koch: Hegel: Die Einheit des Begriffs - Branko Klun: Ontologische Totalität und ethische Differenz bei Lévinas Klaus Müller: Aus der Logik der Subjektivität zur All-Einheit. Dieter Henrichs Weg zu einer Metaphysik bewussten Lebens

Johannes Brachtendorf Geboren 1958; 1992 Promotion; 1998 Habilitation; Inhaber des Lehrstuhls für Philosophische Grundfragen der Theologie an der Katholisch-Theologischen Fakultät der Universität Tübingen.

Stephan Herzberg Geboren 1978; 2008 Promotion; wissenschaftlicher Assistent am Lehrstuhl für Philosophische Grundfragen der Theologie, Tübingen.

Jetzt bestellen:

https://mohrsiebeck.com/buch/einheit-und-vielheit-als-metaphysisches-problem-9783161517495?no_cache=1

order@mohrsiebeck.com

Telefon: $+49(0) 7071-923-17$

Telefax: $+49(0) 7071-51104$ 